\title{
ARTICLE The Dry-aging and Heating Effects on Protein Characteristics of Beef Longissiumus Dorsi
}

\section{OPEN ACCESS}

$\begin{array}{ll}\text { Received } & \text { September 20, } 2018 \\ \text { Revised } & \text { September 21, } 2018 \\ \text { Accepted } & \text { September 27, } 2018\end{array}$

*Corresponding author: Yun-Sang Choi Research Group of Food Processing, Korean Food Research Institute, Wanju 55365, Korea Tel: +82-63-219-9387

Fax: +82-63-219-9076

E-mail: kcys0517@kfri.re.kr

\author{
Ji-Han Kim ${ }^{1}$, Ha-Jung Lee ${ }^{1}$, Dong-Min Shin ${ }^{1}$, Tae-Kyung Kim², Young-Boong Kim², \\ and Yun-Sang $\mathrm{Choi}^{2, *}$ \\ ${ }^{1}$ Department of Food Science and Biotechnology of Animal Resources, Konkuk \\ University, Seoul 05029, Korea \\ ${ }^{2}$ Research Group of Food Processing, Korean Food Research Institute, Wanju 55365, \\ Korea
}

\begin{abstract}
The aim of this study was to investigate the effects of dry-aging (DA) and the cooking process on the myofibril protein functionalities and in vitro digestibility of proteins in beef loin. Six sirloins from beef were dry-aged for $28 \mathrm{~d}$, and the control group $(n=6)$ was analyzed $2 \mathrm{~d}$ postmortem for this study. Dimensional changes (reduction of thickness and surface shrinkage) after cooking were significantly greater in the control group than the DA group, whereas the shear force of the DA group was significantly lower than that of the control. Effect of cooking on aggregation, hydrophobicity, and in vitro digestibility were significantly higher in the DA group than in the control. After cooking, the protein in DA sirloins was more oxidized than in the control samples. According to the sodium dodecyl sulfate-polyacrylamide gel electrophoresis result, the low molecular weight bands (below $17 \mathrm{kDa}$ ) increased in the DA group, finding that the protein characteristics of dry-aged beef was affected by cooking.
\end{abstract}

Keywords dry-aging, cooking, digestibility, beef, aggregation, hydrophobicity

\section{Introduction}

Cooking is one of the main methods for safe preparation of food ingredients such as vegetables and meat. Cooking process on meat and meat products can prevent the spread of food-borne diseases. Although it is an effective way to eat safely, the cooking process can affect the meat protein quality through protein denaturation and degradation (Gao et al., 2009; Murphy and Marks, 2000). Cooking causes that the denaturation of protein dimensional structure and alters the amino acid residues present in meat (Yu et al., 2017). Depends on the meat states (frozen, thawed and fresh), the cooking proved significantly differences for color, cooking loss, shear force and sensory characteristics in meats (Obuz and Dikeman, 2003). Previously, the relationship between moisture content and cooking traits of beefs using a water bath was reported by Oillic et al. (2011). They are reported that the dry-aged beef might be

(C) Korean Society for Food Science of Animal Resources. This is an open access article distributed under the terms of the Creative Commons Attribution Non-Commercial License (http://creativecommons.org/licences/by-nc/3.0) which permits unrestricted non-commercial use, distribution, and reproduction in any medium, provided the original work is properly cited. 
less affected by cooking procedure since the initial moisture content was low in dry-aged beef.

Dry-aged beef has been proven to lower shear force and contain plentiful free amino acids, which are involved in the Maillard reaction, which accounts for improved flavor after cooking (Lee et al., 2017; Obuz et al., 2014). Previously, the limited research on dry-aged beef found that the dry-aging (DA) process, with some modifications, such as different muscles, aging conditions and packaging methods, changes meat quality, and lipid oxidation. However, it may be possible that protein of dry-aged beef was highly affected by the cooking process compared to fresh meat protein, since the protein was denatured/degraded by proteolysis during DA.

Although the DA does have positive effects on sensory characteristics as the above mentioned results, there has been limited studies determining how the interaction between DA and cooking affects the protein characteristics and digestion of beef. We speculated that the DA and heating provide significant effects on protein characteristics. Therefore, the objective of this study was to compare the protein characteristics of fresh and dry-aged beef after heating. Our study could provide basic knowledge of the DA and heating effects on protein characteristics of beef longissiumus dorsi.

\section{Material and Methods}

\section{Dry aged meat}

Sirloins at 2 d postmortem, from a total of 6 Holstein steers (quality grade 2, approximately 26 months age), were purchased from a commercial slaughterhouse. The samples were bisected, and randomly assigned into two groups, a control and dry-aged beef $(n=6)$. Dimensional changes, cooking rate $(\mathrm{CR})$ and shear force of fresh samples were immediately measured. For dry-aged beef, the sirloin was hung in a refrigerated room with ventilation. The condition of DA was $1^{\circ} \mathrm{C}$, relative humidity about $85 \%$, and $0.5-1.5 \mathrm{~m} / \mathrm{s}$ of air circulation for $28 \mathrm{~d}$ (Dashdorj et al., 2016). The myofibril protein was immediately extracted from the fresh and dry-aged samples, and frozen at $-80^{\circ} \mathrm{C}$ for further analyses.

\section{Dimensional changes, cooking rate and shear force}

Samples at $4^{\circ} \mathrm{C}$ were cut into cube shapes $(3 \times 3 \times 2.54 \mathrm{~cm}$, diameter $\times$ diameter $\times$ thickness $)$ and then cooked at $145^{\circ} \mathrm{C}$ using preheated electronic grills. The core temperature of samples reached $71.1^{\circ} \mathrm{C}$, as measured using a digital thermocouple machine (Tes-1305, Tes Electrical Co., Taiwan) equipped with a data logger (RS-232, Tes Electrical Co., Taiwan). Dimensional changes were calculated as percentages of changes of thickness and surface shrinkage. The CR was expressed as ${ }^{\circ} \mathrm{C} / \mathrm{min}$. After cooking, the core samples were collected parallel to the muscle fiber shape by using a $1.27 \mathrm{~cm}$ diameter handed coring device, and the shear force was measured using a TA-XT2i (Stable Micro System Ltd., Surrey, UK) equipped with a triangle angular slot cutting edge under a crosshead speed of $1.5 \mathrm{~mm} / \mathrm{s}$ (Kim et al., 2017).

\section{In vitro digestibility}

In vitro gastrointestinal digestion model was conducted in specific steps, with four phases (mouth, gastric, duodenal, and bile juices), as described by Kim and Hur (2018). The protein digestibility in the cooked beef during simulated human gastrointestinal digestion was measured by the infiltration rates of the dialysis tubing and expressed as the percentage of protein concentration inside and outside the dialysis tubing. The protein concentration was measured by the Biuret method. 
MFI measurement was conducted using the method of Culler et al. (1978).

\section{Aggregation and hydrophobicity}

The myofibril protein extracts were used to assess protein functionalities (aggregation and hydrophobicity) and oxidation (carbonyl and sulfhydryl content). Before the aggregation and hydrophobicity measurements, the myofibril protein concentration was adjusted at $0.1 \mathrm{mg} / \mathrm{mL}$. Hydrophobicity of the myofibril protein was measured using the Bromophenol Blue (BPB) bound ability according to Chelh et al. (2006). The aggregation of the myofibril protein was determined using Nile Red to fluoresce the aggregates after binding in accordance with the method of Demeule, Gurny, and Arvinte (2007). Optimum excitation $\left(\lambda_{\mathrm{ex}}\right)$ and emission $\left(\lambda_{\mathrm{em}}\right)$ wavelengths were $560 \mathrm{~nm}$ and $620 \mathrm{~nm}$, respectively. The intensity of fluorescence was expressed as arbitrary units (au).

\section{Protein oxidation (carbonyl and sulfhydryl contents)}

Carbonyl content measurement of myofibril protein was carried out in accordance with the method of Vossen and De Smet (2015). Sulfhydryl content of myofibrillar proteins was determined after derivatization by Ellman's reagent with 5,5'dithiobis(2-nitrobenzoic acid) (DTNB), according to Jornberg et al. (2013). The sulfhydryl content was expressed as nM/ mg protein.

\section{SDS-PAGE}

The protein degradation (each sample $0.5 \mathrm{mg}$ protein/ $\mathrm{mL}$ ) in meat was evaluated by $12 \%$ sodium dodecyl sulfatepolyacrylamide gel electrophoresis (SDS-PAGE) according to the method of Laemmli (1970). Samples (0.67\%) and Laemmli sample buffer (Bio-Rad Lab, Inc., USA) was mixed. The mixtures were heated to $100^{\circ} \mathrm{C}$ for $5 \mathrm{~min}$, and $15 \mu \mathrm{L}$ of each sample was injected into the wells of a 12\% Mini-PROTEAN ${ }^{\circledR}$ TGX $^{\mathrm{TM}}$ Precast Gel (Bio-Rad Lab, Inc., USA). The loaded gel was stained using Coomassie Brilliant Blue R250 (B7920, Sigma, USA). The separated protein bands were identified by comparing with those of standard protein markers (Precision Plus Protein Standards, Catalog number 1610374, Bio-Rad Lab., USA).

\section{Statistical analysis}

Six muscles per treatment (control and dry-aged beef) and cooking process (uncooked and cooked meat) were used as experimental units. Statistical analysis was performed using two-way analysis of variance (ANOVA), followed with paired Student's t-tests to determine the effects of DA and cooking on protein characteristic differences $(p<0.05)$, whereas one-way ANOVA was carried out on the reduction of diameter and thickness, shear force and CR. Pearson correlation coefficients were collected with the measured variables as a 95\% confidence level. The statistical analysis was conducted using SPSS version 19.0 .

\section{Results and Discussion}

Means for the percentage of thickness and surface reduction, shear force and CR of dry-aged beef loin are shown in Table 1. The thickness of the control group showed greater reduction $(\mathrm{p}<0.01)$ relative to dry-aged beef $(-10.03 \%$ and $-0.17 \%$, respectively). In addition, the dry-aged beef lost significantly less in surface (9.91\%) compared to the control group $(17.02 \%)$. Dimensional changes of meat could have occurred by the loss of water, resulting in the protein denaturation and 
Table 1. Effect of dry-aging and cooking process on dimensional reduction (\%), shear force, cooking rate, MFI, myofibril protein functionalities (aggregation and hydrophobicity), in vitro digestibility (\%), and protein oxidation of raw and cooked beef loins

\begin{tabular}{|c|c|c|c|c|c|c|c|}
\hline & \multicolumn{2}{|c|}{ Dry-aging } & \multicolumn{2}{|c|}{ Cooking } & \multicolumn{3}{|c|}{ p-value } \\
\hline & Control & $\mathrm{DA}$ & Non-cooked & Cooked & Dry-aging & Cooking & Interaction \\
\hline \multicolumn{8}{|l|}{ Reduction (\%) } \\
\hline Thickness & -10.03 & -0.17 & - & - & 0.060 & - & - \\
\hline Surface & 17.02 & 9.91 & - & - & 0.004 & - & - \\
\hline Shear force $(\mathrm{kg})$ & 3.23 & 2.52 & - & - & $<0.001$ & - & - \\
\hline Cooking rate $\left({ }^{\circ} \mathrm{C} / \mathrm{min}\right)$ & 8.14 & 7.23 & - & - & 0.237 & - & - \\
\hline Nile red fluorescence (a.u.. $)^{1)}$ & 12.40 & 16.13 & 10.05 & 17.48 & 0.015 & $<0.001$ & 0.040 \\
\hline Bound BPB $(\mu g)^{2)}$ & 8.23 & 8.94 & 7.77 & 9.40 & 0.473 & 0.114 & 0.011 \\
\hline MFI & 42.45 & 46.21 & 49.88 & 38.77 & 0.043 & $<0.001$ & 0.236 \\
\hline In vitro digestibility (\%) & 97.67 & 97.74 & 97.72 & 98.69 & 0.002 & 0.067 & 0.428 \\
\hline Sulfhydryl content $\left.{ }^{3}\right)$ & 27.46 & 32.79 & 32.90 & 27.35 & 0.019 & 0.015 & 0.015 \\
\hline Carbonyl content ${ }^{3}$ ) & 0.09 & 1.08 & 0.61 & 1.25 & $<0.001$ & 0.014 & 0.007 \\
\hline
\end{tabular}

1) Nile red fluorescence, aggregation, ${ }^{2)}$ Bound $\mathrm{BPB}$, hydrophobicity, ${ }^{3)}$ unit, $\mathrm{nM} / \mathrm{mg}$ protein. $\mathrm{BPB}$, bromophenol blue; MFI, myofibrillar fragment index.

cell membrane destruction during cooking, in agreement with Ritchey and Hosterler (1964), and Rowe (1989). However, the dry-aged beef contained lower moisture content than the non-aged beef due to the evaporation of moisture in meat during aging (Obuz et al., 2014). Decreased moisture content for dry-aged beef were reported by Berger et al. (2018). In agreement with Oillic et al. (2011), the dimensional changes of dry-aged beef might be less affected by cooking procedure since the initial moisture content was low in dry-aged beef, regardless of the protein denaturation.

Dry aging decreased shear force compared to the control group (3.23 and $5.25 \mathrm{~kg}, \mathrm{p}<0.001)$. The lower shear force of dryaged beef can be explained by the high proteolysis index compared to the control group, which showed similarity to the results reported by Lee et al. (2017).

The CR from $4^{\circ} \mathrm{C}$ to $71.1^{\circ} \mathrm{C}$ of the meat was numerically different between the control and dry-aged beef $\left(8.14^{\circ} \mathrm{C}\right.$ and $7.23^{\circ} \mathrm{C} / \mathrm{min}$, respectively), but not significant ( $\left.\mathrm{p}>0.05\right)$. The $\mathrm{CR}$ could be related to the amount of moisture, which has high thermal conductivity. Similarly, Elansari and Hobani (2009) found that thermal conductivity of meat linearly increased with moisture content.

Aging and cooking effects on myofibrillar fragment index (MFI), protein functionalities (aggregation and hydrophobicity) and in vitro digestibility are presented in Table 1. Interacting effects of treatment and cooking on protein aggregation and hydrophobicity were detected. With cooking, the protein aggregation and hydrophobicity of dry-aged beef rapidly increased, in agreement with Traore et al. (2012). The increase in the aggregation and hydrophobicity in dry-aged beef could be associated with protein cross-linking, fragmentation, and a part of amino acid residual exposure from the protein surface to outside due to protein denaturation (Lund et al., 2011). Therefore, it seemed that the protein surface area increased by the protein fragmentation, with the result that the protein from dry-aged beef may be highly reactive to thermal processing. Similarly, Bax et al. (2012) demonstrated that the number of particles in myofibril extract increased in aged meat due to proteolysis. The significant increase of MFI $(\mathrm{p}<0.05)$ in dry-aged beef occurred by proteolysis during aging time, whereas the MFI significantly decreased by cooking, regardless of the treatment. Dry-aged beef showed significantly higher in vitro 
protein digestibility compared to the control group, and the in vitro protein digestibility of both groups increased after cooking $(\mathrm{p}<0.05)$. However, the gap in the in vitro protein digestibility was numerically too small to be significant, although there was a significant difference in the in vitro protein digestibility values between commercial and dry-aged beef $(96.67 \%$ and $96.74 \%$, respectively). Mora et al. (2017) have described that aging and cooking increased the intensity of small peptides in meat after digestion, and shows functionalities, such as lowering blood pressure and antioxidant effects.

Dry-aging and cooking effects on protein oxidation of beef loin are shown in Table 1. Sulfhydryl content of myofibril protein from DA was initially higher than that of myofibril protein from the control $(p<0.05)$. Sulfhydryl contents of both groups decreased after cooking, and the interaction effect was detected $(\mathrm{p}<0.05)$. Sulfhydryl content of dry-aged beef was more affected than that of the control group by cooking. The disulfide bond between some proteins could be disconnected by proteolysis in dry-aged beef, making it easier to be oxidized by radical species during cooking (Hofmann and Hamm, 1978). There is a trend of the sulfhydryl and disulfide bonds increasing during the initial phase of protein oxidation (Opstvedt et al., 1984). The loss of sulfhydryl and the formation of carbonyl compounds reflected the protein oxidation status (Soyer et al., 2010). Likewise, the carbonyl content of dry-aged beef was significantly higher than that of the control groups, and the cooking process led to the formation of carbonyl content $(\mathrm{p}<0.05)$. The carbonyl content of the control group rapidly increased compared to dry-aged beef, which was not significantly increased, during cooking. The formation of carbonyl compounds did not increase further beyond approximately $70^{\circ} \mathrm{C}$ of cooking temperature (Bax et al., 2012; Gatellier et al., 2007). Watanabe et al. (2015) suggested that the carbonyl compounds, such as aldehydes, alcohol, and ketones, increased when aged beef was cooked at $180^{\circ} \mathrm{C}$. In this regard, it could be speculated that the aged beef with different cooking temperature might affect protein denaturation, resulting in different patterns.

The SDS-PAGE of raw and aged beef treated with cooking is shown in Fig. 1. From the heavy myosin chain to light myosin chains (the high molecular weight to low molecular weight), the band segmentation of dry-aged beef was clearly observed. G-Actin (a molecular weight of $42 \mathrm{kDa}$ ) decreased in both groups with cooking, in agreement with Murphy and Marks (2000). This result agreed with that of Murphy et al. (1998), in which a decrease in the $<43 \mathrm{kDa}$ band was detected at the cooking temperature range of $60^{\circ} \mathrm{C}$ to $80^{\circ} \mathrm{C}$ in chicken breast patties. In this study, SDS-PAGE revealed that the protein of

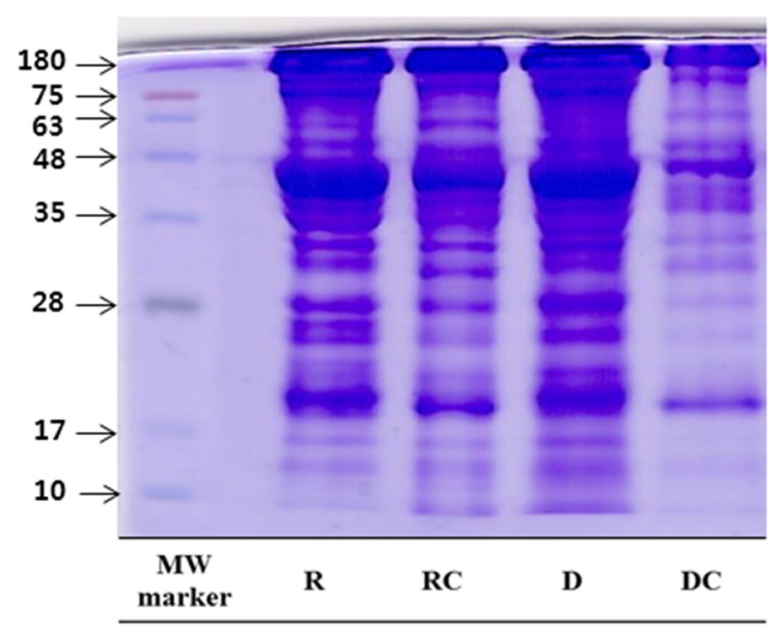

Fig. 1. SDS-PAGE patterns of non-aged beef and dry-aged beef with treated cooking process. Vertical numbers indicate molecular weight marker in kDa. R, non-aged beef; RC, non-aged beef with cooking; D, dry-aged beef; DC, dry-aged beef with cooking; SDS-PAGE, sodium dodecyl sulfate-polyacrylamide gel electrophoresis. 
dry-aged beef was sensitively affected by cooking, resulting in the high protein degradation of dry-aged beef. In particular, the $<20 \mathrm{kDa}$ band, which might include myosin light chain-1 (MLC-1) and myosin light chain fragments, increased in the dry-aged beef. In agreement with the SDS-PAGE protein separation patterns reported by Claeys et al. (2004), a range of 3 to $17 \mathrm{kDa}$ proteins in beef increased with an increasing aging time. This was evident in the degree of protein degradation in dryaged beef and denaturation by cooking.

Pearson correlations among the cooking traits and protein characteristics are shown in Table 2. In terms of dimensional changes, there was a negative correlation between surface and dimension reductions $(\mathrm{p}<0.001)$. Shear force showed a negative correlation with the thickness reduction and a positive correlation with the surface reduction, respectively $(\mathrm{p}<0.001)$. Shear force had a negative correlation with carbonyl content $(\mathrm{p}<0.001)$. Moreover, a highly negative correlation between nile red (aggregation) and digestibility was observed $(\mathrm{p}<0.001)$. In addition, BPB exhibited a negative correlation with sulfhydryl content $(\mathrm{p}<0.001)$, and carbonyl showed a negative correlation with sulfhydryl content $(\mathrm{p}<0.001)$.

\section{Conclusion}

Myofibrillar protein degradation of dry-aged beef increased, with decreasing shear force compared to commercial beef, as expected. In terms of protein functionalities, the aggregation of dry-aged beef increased, while its hydrophobicity was not affected by dry-aging. Before cooking, the carbonyl content increased in dry-aged beef, but the sulfhydryl content did not show a difference between commercial and dry-aged beef. However, the protein oxidation of dry-aged beef was sensitively affected by the cooking process. Moreover, the in vitro protein digestibility of dry-aged beef was slightly improved compared to the commercial beef.

\section{Acknowledgements}

This research was supported by Main Research Program (E0186901-01) of the Korea Food Research Institute (KFRI) funded by the Ministry of Science and ICT (Korea). This research was also partially supported Agri-Bio Industry Technology

Table 2. Pearson correlation coefficients and probabilities of dry aging and cooking effects on dimensional changes, shear force, cooking rate (CR), aggregation (Nile red), hydrophobicity (BPB), MFI, digestibility, sulfhydryl and carbonyl contents of beef loins

\begin{tabular}{|c|c|c|c|c|c|c|c|c|c|c|}
\hline & Thickness & Surface & Shear force & $\mathrm{CR}$ & Nile red & BPB & MFI & Digestibility & Sulfhydryl & Carbonyl \\
\hline Thickness & 1.000 & $-0.739^{* *}$ & $-0.551^{* *}$ & 0.176 & -0.228 & 0.096 & -0.215 & 0.195 & 0.180 & 0.298 \\
\hline Surface & & 1.000 & $0.634^{* *}$ & 0.025 & 0.140 & -0.108 & 0.290 & -0.265 & -0.369 & -0.406 \\
\hline Shear force & & & 1.000 & -0.256 & 0.012 & -0.231 & 0.312 & -0.165 & -0.276 & $-0.535^{* *}$ \\
\hline $\mathrm{CR}^{1)}$ & & & & 1.000 & -0.132 & 0.186 & -0.044 & 0.204 & -0.054 & 0.085 \\
\hline Nile red & & & & & 1.000 & -0.083 & -0.253 & $-0.562^{* *}$ & -0.257 & -0.393 \\
\hline $\mathrm{BPB}^{2)}$ & & & & & & 1.000 & -0.397 & 0.247 & $-0.560^{* *}$ & 0.046 \\
\hline $\mathrm{MFI}^{3)}$ & & & & & & & 1.000 & 0.028 & 0.309 & 0.137 \\
\hline Digestibility & & & & & & & & 1.000 & 0.162 & 0.299 \\
\hline Sulfhydryl & & & & & & & & & 1.000 & $-0.044^{*}$ \\
\hline
\end{tabular}

${ }^{*} \mathrm{p}<0.05,{ }^{* *} \mathrm{p}<0.01$.

${ }^{1)} \mathrm{CR}$, cooking rate, ${ }^{2)} \mathrm{BPB}$, bromophenol blue, ${ }^{3)} \mathrm{MFI}$, myofibrillar fragmentation index. 
Development Program (317001-3) by the Ministry of Agriculture, Food and Rural Affairs (Korea).

\section{References}

Bax ML, Aubry L, Ferreira C, Daudin JD, Gatellier P, Rémond D, Santé-Lhoutellier, V. 2012. Cooking temperature is a key determinant of in vitro meat protein digestion rate: Investigation of underlying mechanisms. J Agric Food Chem 60:25692576.

Berger J, Kim YHB, Legako JF, Martini S, Lee J, Ebner P, Zuelly SMS. 2018. Dry-aging improved meat quality attributes of grass-fed beef loins. Meat Sci 145:285-291.

Chelh I, Gatellier P, Santé-Lhoutellier V. 2016. Technical note: A simplified procedure for myofibril hydrophobicity determination. Meat Sci 74:681-684.

Claeys M, Graham B, Vas G, Wang W, Vermeylen R, Pashynska V, Cafmeyer J, Guyon P, Andreae MO, Artaxo P, Maenhaut W. 2004. Formation of secondary organic aerosols through photooxidation of isoprene. Science 303:1173-1176.

Culler RD, Parrish FC, Jr. Smith GC, Cross HR. 1978. Relationship of myofibril fragmentation index to certain chemical, physical, and sensory characteristics of bovine longissimus muscle. J Food Sci 43:1177-1180.

Dashdorj D, Tripathi VK, Cho S, Kim Y, Hwang I. 2016. Dry aging of beef: Review. J Anim Sci Technol 58:20.

Demeule B, Gurny R, Arvinte T. 2007. Detection and characterization of protein aggregates by fluorescence microscopy. Int J Pharm 329:37-45.

Elansari AM, Hobani AI. 2009. Effect of temperature and moisture content on thermal conductivity of four types of meat. Int J Food Prop 12:308-315.

Gao H, Mao M, Liang C, Lin C, Xiang J. 2009. Detection of the end point temperature of thermal denatured protein in fish and chicken meat through SDS-PAGE electrophoresis. J Ocean Univ China 8:95-99.

Gatellier P, Gomez S, Gigaud V, Berri C, Bihan-Duval EL, Santé-Lhoutellier V. 2007. Use of a fluorescence front faces technique for measurement of lipid oxidation during refrigerated storage of chicken meat. Meat Sci 76:543-547.

Hofmann K, Hamm R. 1978. Sulfhydryl and disulfide groups in meats. Adv Food Res 24:1-111.

Jongberg S, Tørngren MA, Gunvig A, Skibsted LH, Lund MN. 2013. Effect of green tea or rosemary extract on protein oxidation in Bologna type sausages prepared from oxidatively stressed pork. Meat Sci 93:538-546.

Kim HS, Hur SJ. 2018. Effect of six different starter cultures on the concentration of residual nitrite in fermented sausages during in vitro human digestion. Food Chem 239:556-560.

Kim TK, Hong SH, Ku SK, Kim YB, Jeon KH, Choi HD, Park JD, Park KS, Choi YS. 2017. Quality characteristics of tteokgalbi with black rice bran and organic acid to substitute synthetic caramel colorant. Korean J Food Sci An 37:552560.

Laemmli UK. 1970. Cleavage of structural proteins during assembly of head of bacteriophage-T4. Nature 227:680-685.

Lee HJ, Choe J, Kim KT, Oh J, Lee DG, Kwon KM, Choi YI, Jo C. 2017. Analysis of low-marbles Hanwoo cow meat aged with different dry-aging methods. Asian-Australas J Anim Sci 30:1733-1738.

Lund MN, Heinonen N, Baron CP, Estevez M. 2011. Protein oxidation in muscle foods: A review. Mol Nutr Food Res 55:8395.

Mora L, Bolumar T, Heres A, Toldrá F. 2017. Effect of cooking and simulated gastrointestinal digestion on the activity of generated bioactive peptides in aged beef meat. Food Funct 8:4347-4355. 
Murphy RY, Marks BP. 2000. Effect of meat temperature on proteins, texture, and cook loss for ground chicken breast patties. Poult Sci 79:99-104.

Murphy RY, Marks BP, Marcy JA. 1998. Specific heat of chicken breast patties and their constituent proteins by differential scanning calorimetry. J Food Sci 63:88-91.

Obuz E, Akkaya L, Gok V, Dikeman ME. 2014. Effects of blade tenderization, aging method and aging time on meat quality characteristics of Longissimus lumborum steaks from cull Holstein cows. Meat Sci 96:177-1232.

Obuz E, Dikeman ME. 2003. Effects of cooking beef muscles from frozen or thawed states on cooking traits and palatability. Meat Sci 65:993-997.

Oillic S, Lemoine E, Gros JB, Kondjoyan A. 2011. Kinetic analysis of cooking losses from beef and other animal muslces heated in a water bath-Effect of sample dimensions and prior freezing and ageing. Meat Sci 88:338-346.

Opstvedt J, Miller R, Hardy RW, Spinelli J. 1984. Heat-induced changes in sulfhydryl groups and disulfide bonds in fish protein and their effect on protein and amino acid digestibility in rainbow trout (Salmo gairdneri). J Agric Food Chem 32:929-935.

Ritchey SJ, Hostetler RL. 1964. Relationships of free and bound water to subjective scores for juiciness and softness and to changes in weight and dimensions of steaks from two beef muscles during cooking. J Food Sci 29:413-419.

Rowe RWD. 1989. Electron microscopy of bovine muscles: II - The effects of heat denaturation on post rigor sarcolem and endomysium. Meat Sci 26:281-294.

Soyer A, Özalp B, Dalmis Ü, Bilgin V. 2010. Effects of freezing temperature and duration of frozen storage on lipid and protein oxidation in chicken meat. Food Chem 120:1025-1030.

Traore S, Aubry L, Gatellier P, Przybylski W, Jaworska D, Kajak-Siemaszko K, Santé-Lhoutellier V. 2012. Higher drip loss is associated with protein oxidation. Meat Sci 90:917-924.

Vossen E, De Smet S. 2015. Protein oxidation and protein nitration influenced by sodium nitrite in two different meat model systems. J Agric Food Chem 63:2550-2556.

Watanabe A, Kamada G, Imanari M, Shiba N, Yonai M, Muramoto T. 2015. Effect of aging on volatile compounds in cooked beef. Meat Sci 107:12-19.

Yu TY, Morton JD, Clerens S, Dyer JM. 2017. Cooking-induced protein modifications in meat. Compr Rev Food Sci Food Saf 16:141-159. 